\title{
Uso do resíduo de catalisador de processo de craqueamento catalítico fluído de hidrocarbonetos em refratários silicoaluminosos
}

\section{(Use of catalyst waste from hydrocarbon fluid catalytic cracking process in alumina-silica refractories)}

\author{
L.P. Garcia ${ }^{1}$, R. T. da Cruz ${ }^{2}$, S. R. Bragança ${ }^{2}$ \\ ${ }^{1}$ Refinaria Alberto Pasqualini - REFAP S/A, Av. Getúlio Vargas 11001, Canoas, RS 92420-221 \\ ${ }^{2}$ DEMAT, Universidade Federal do Rio Grande Sul -UFRGS, Av. Osvaldo Aranha 99/705, Porto Alegre, RS 90035-190 \\ saulorb@ufrgs.br
}

\begin{abstract}
Resumo
Este trabalho objetivou o desenvolvimento de metodologia para o aproveitamento do resíduo de catalisador de craqueamento de hidrocarbonetos, na produção de refratários silicoaluminosos. Esse resíduo foi utilizado em substituição às matérias-primas convencionais, com o conseqüente ganho ambiental e econômico. Com base em composições químicas e mineralógicas, foram selecionadas formulações de massas refratárias, as quais foram queimadas em temperaturas similares às utilizadas para queima de refratários silicoaluminosos comerciais. A análise das propriedades tecnológicas apresentadas, dentre as formulações propostas, definiu que a formulação que continha $15 \%$ em peso de catalisador gasto, obteve as melhores características, sendo estas semelhantes às de um material refratário comercial.

Palavras-chave: refratários, resíduo de catalisador.
\end{abstract}

\begin{abstract}
This work aimed the development of methodology for the utilization of the residue of catalyst from of hydro-carbons catalytic cracking process in the production of alumina-silica refractory. This residue was used in substitution of part of conventional raw materials, with the consequent ambient and economic profit. It was selected some formulations based on the chemical and mineralogical compositions of refractory masses. They were fired in similar temperatures to the ones used for production of commercial refractories. The analysis of the technological properties of the formulations proposed, defined that the composition that contained $15 \%$ wt of catalyst waste got the best characteristics. The final product showed technical parameters similar to the ones of commercial refractory material.
\end{abstract}

Keywords: refractories, catalyst waste.

\section{INTRODUÇÃO}

O catalisador é o elemento fundamental no processo de craqueamento catalítico fluído, pois é ele que promove as rupturas e rearranjos das moléculas de hidrocarbonetos em condições mais brandas de temperatura e de pressão, aumentando os rendimentos e a qualidade da gasolina e do GLP (gás liquefeito de petróleo) [1].

No Brasil, o catalisador de craqueamento catalítico fluído é classificado segundo a norma ABNT-NBR 10004 [2] como resíduo não-inerte (classe II). A principal forma de aproveitamento desse material é a utilização em cimenteiras, onde fazem parte do clínquer. Nas altas temperaturas reinantes nos fornos de clínquer, o coque é eliminado e a matéria inorgânica é convertida em formas inertes após o emprego do cimento produzido [3].

$\mathrm{O}$ catalisador utilizado em unidades de craqueamento catalítico fluído é um granulado muito fino, constituído basicamente de: um componente ativo (zeólita); uma matriz ativa (alumina); uma matriz inerte (caulim); uma matriz sintética (sílica) e ingredientes funcionais [1]. Esses catalisadores possuem um teor de alumina dentro da faixa de interesse para as matérias-primas usadas na produção de refratários silicoaluminosos $[4,5]$. Em vista deste fato, o presente trabalho buscou explorar a possibilidade de se desenvolver um material refratário, empregando-se como matéria-prima argilas caoliníticas e o resíduo de catalisador (catalisador gasto). Este é gerado em unidade de craqueamento catalítico fluído de hidrocarbonetos na Refinaria Alberto Pasqualini S/A.

A proposta deste trabalho consiste no desenvolvimento de uma metodologia de aproveitamento de rejeitos, em substituição a materiais tradicionais de fontes normalmente não renováveis, possibilitando: reduzir o impacto ambiental da exploração desses materiais tradicionais; reduzir o impacto ambiental causado pela administração incorreta dos rejeitos, ou o risco de acidentes ambientais quando armazenados de forma incorreta; e, se possível, reduzir os custos monetários dos produtos. 


\section{MATERIAIS E MÉTODOS}

Inicialmente as matérias-primas foram caracterizadas pelos ensaios de fluorescência de raios $X$, difração de raios $\mathrm{X}$, análise térmica diferencial, termogravimetria e granulometria. Esta primeira etapa possibilitou, por exemplo, a confirmação de que o catalisador gasto apresenta teores de alumina e de sílica dentro da faixa de interesse de matériasprimas para a manufatura de refratários.

$\mathrm{Na}$ etapa seguinte foram manufaturados corpos-de-prova de caulim com teores crescentes de catalisador gasto, de forma a verificar a influência da temperatura de sinterização e da adição do catalisador sobre as propriedades dos refratários obtidos. A seguir, com o intuito de se reproduzir uma composição comercial, procedeu-se o acréscimo de chamota e argila plástica à melhor formulação de caulim + catalisador. O refratário assim obtido, com a formulação contendo caulim, catalisador gasto, chamota e argila plástica, foi caracterizado tecnologicamente. Por fim, realizou-se a investigação da microestrutura, por microscopia eletrônica de varredura (MEV), relacionando-a com as propriedades obtidas desses refratários.

\section{Caracterização química e mineralógica}

Os resultados obtidos por fluorescência de raios X, das composições químicas das matérias-primas utilizadas na manufatura dos corpos-de-prova, estão descritos na Tabela I.

Tabela I - Composição química das matérias-primas. [Table I - Raw materials chemical composition.]

\begin{tabular}{cccc}
\hline$(\%)$ & $\begin{array}{c}\text { Catalisador } \\
\text { gasto }\end{array}$ & Caulim & $\begin{array}{c}\text { Argila } \\
\text { Plástica }\end{array}$ \\
\hline $\mathrm{SiO}_{2}$ & 51,05 & 50,09 & 57,00 \\
$\mathrm{Al}_{2} \mathrm{O}_{3}$ & 32,10 & 36,50 & 25,87 \\
$\mathrm{La}_{2} \mathrm{O}_{3}$ & 5,72 & ----- & ----- \\
$\mathrm{CaO}$ & 2,66 & 0,01 & 0,30 \\
$\mathrm{Fe}_{2} \mathrm{O}_{3}$ & 2,36 & 0,77 & 0,97 \\
$\mathrm{~V}_{2} \mathrm{O}_{5}$ & 1,67 & ---- & ---- \\
$\mathrm{NiO}$ & 1,62 & ---- & ---- \\
$\mathrm{P}_{2} \mathrm{O}_{5}$ & 0,90 & ----- & ----- \\
$\mathrm{CeO}_{2}$ & 0,78 & ----- & ----- \\
$\mathrm{K}_{2} \mathrm{O}$ & 0,11 & 1,48 & 0,81 \\
$\mathrm{TiO}_{2}$ & 0,55 & 0,06 & 1,08 \\
$\mathrm{Perda}$ ao Fogo & 0,48 & 11,9 & 13,97 \\
\hline
\end{tabular}

As fases no catalisador gasto (Fig. 1) são: a boemita e um aluminossilicato hidratado. Este aluminossilicato hidratado pode ser de cálcio, que está presente no catalisador gasto com um teor de 2,66\% e/ou, segundo Santos [6], pode ser uma argila pirolisada contendo lantânio ou cério interlamelar, que totalizam $6,5 \%$ em massa do catalisador gasto. As fases detectadas no caulim e na argila plástica foram a caolinita, o quartzo e a illita.

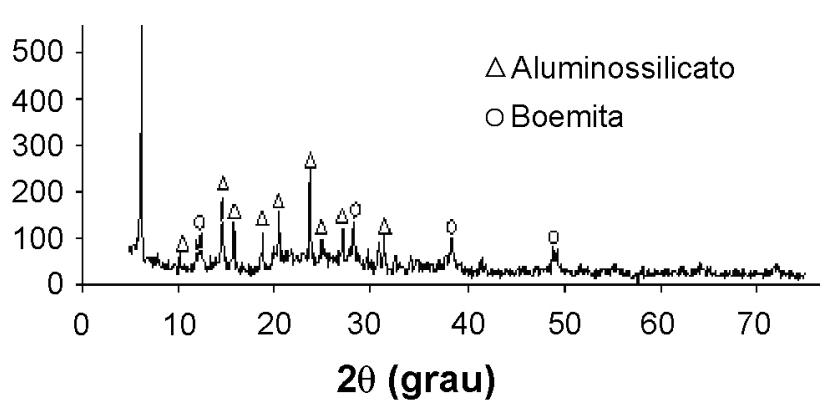

Figura 1: Difratograma de raios $\mathrm{X}$ do catalisador gasto. [Figure 1: X-ray diffraction pattern of catalyst waste.]

\section{Analise térmica diferencial e análise termogravimétrica}

A análise térmica diferencial e gravimétrica do catalisador gasto pode ser visualizada na Fig. 2. A umidade do catalisador gasto evaporou durante o aquecimento até aproximadamente $140{ }^{\circ} \mathrm{C}$. Entre $250{ }^{\circ} \mathrm{C}$ e $900{ }^{\circ} \mathrm{C}$, ocorre a perda gradual de massa, sugerindo a perda de compostos carbônicos e da água de hidratação, das fases como aluminossilicato e boemita, sendo os primeiros de reação exotérmica e os segundos endotérmicos. $\mathrm{O}$ pico exotérmico formado em cerca de $1100{ }^{\circ} \mathrm{C}$ está associado a transformações mineralógicas, possivelmente de mulitização.

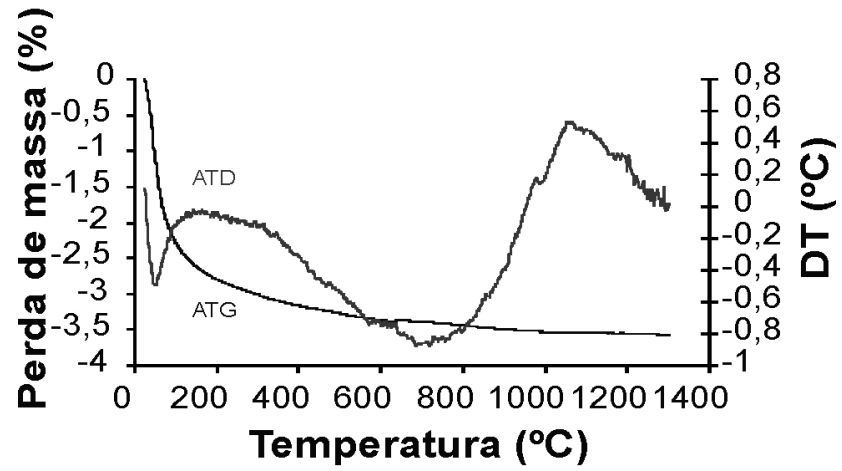

Figura 2: Curvas de análise térmica diferencial e termogravimétrica do catalisador gasto (taxa de aquecimento de $10{ }^{\circ} \mathrm{C} / \mathrm{min}$.).

[Figure 2: Differential thermal analysis and themogravimetric curves of catalyst waste (heating rate $10^{\circ} \mathrm{C} / \mathrm{min}$ ).]

Tabela II - Distribuição de tamanhos de partículas do caulim, catalisador gasto e argila plástica.

[Table II - Particle size distribution of kaolin, catalyst waste and ball clay.]

\begin{tabular}{lcccc}
\hline Amostras & $\begin{array}{c}\mathrm{D}_{10} \\
(\mu \mathrm{m})\end{array}$ & $\begin{array}{c}\mathrm{D}_{50} \\
(\mu \mathrm{m})\end{array}$ & $\begin{array}{c}\mathrm{D}_{90} \\
(\mu \mathrm{m})\end{array}$ & $\begin{array}{c}\mathrm{D}_{\text {médio }} \\
(\mu \mathrm{m})\end{array}$ \\
\hline Caulim & 8,6 & 34,2 & 61,2 & 34,9 \\
Catalisador gasto & 39,3 & 66,8 & 104,9 & 69,6 \\
Argila plástica & 0,8 & 3,4 & 14,6 & 5,8 \\
\hline
\end{tabular}

\section{Granulometria}

Na Tabela II tem-se a análise de distribuição granulométrica realizada por difração a laser. Nota-se que o diâmetro médio de partícula apresentado pelas matérias-primas foi de $34,89 \mu \mathrm{m}$ 
para o caulim, 69,56 $\mu \mathrm{m}$ para o catalisador gasto e 5,80 $\mu \mathrm{m}$ para a argila plástica. De um modo geral o catalisador se apresenta no formato de microesfera

\section{Preparação dos corpos-de-prova}

As matérias-primas para fabricação dos corpos-de-prova foram: Caulim comercial, catalisador gasto, argila refratária plástica comercial. Para a formulação E (Tabela III), utilizou-se chamota confeccionada a partir de peças quebradas da amostra A. A necessidade de se acrescentar chamota foi determinada durante a realização dos ensaios, uma vez que o catalisador não apresentou o efeito de chamota esperado, ou seja, não atuou como inibidor da retração das peças. Ao mesmo tempo, constatou-

Tabela III - Composição das formulações. [Table III - Formulation compositions.]

\begin{tabular}{cccccc}
\hline Matéria Prima & A & B & C & D & E \\
\hline Caulim & 100 & 95 & 90 & 85 & 35 \\
Catalisador Gasto & 0 & 5 & 10 & 15 & 15 \\
Chamota & 0 & 0 & 0 & 0 & 40 \\
Argila Plástica & 0 & 0 & 0 & 0 & 10 \\
\hline
\end{tabular}

se que maiores teores de catalisador prejudicavam a cor dos produtos, de modo a torná-los inviáveis comercialmente.

As matérias-primas foram dosadas de acordo com a Tabela III, e homogeneizadas em moinho periquito durante aproximadamente $3 \mathrm{~min}$. As formulações sem argila plástica foram umidificadas com água + álcool polivinílico (PVA) e a formulação contendo argila plástica foi umidificada com água.

Para a conformação dos corpos-de-prova, foi utilizado o método de prensagem uniaxial. Os corpos-de-prova de cada formulação foram feitos na forma de paralelepípedo de dimensões aproximadas de $60 \mathrm{~mm}$ x $20 \mathrm{~mm}$ x $7 \mathrm{~mm}$ em uma prensa hidráulica. Após, eles foram secos ao ar durante $24 \mathrm{~h} \mathrm{e}$ em estufa a $110{ }^{\circ} \mathrm{C}$ por mais $24 \mathrm{~h}$. Os corpos-de-prova foram queimados num forno elétrico nas temperaturas de $1200{ }^{\circ} \mathrm{C}$, $1300{ }^{\circ} \mathrm{C}$ e $1400{ }^{\circ} \mathrm{C}$, com uma taxa de aquecimento de $150 \mathrm{~K} / \mathrm{h}$ e um tempo de patamar de $30 \mathrm{~min}$. Posteriormente, realizou-se os testes de caracterização de acordo com as normas técnicas ABNT-NBR [7-10].

\section{RESULTADOS E DISCUSSÃO}

Caracterização tecnológica dos corpos-de-prova com formulação contendo caulim e catalisador gasto

Os corpos cerâmicos com as composições A, B, C e D

Tabela IV - Caracterização técnica das composições A, B, C e D a seco e queimadas nas temperaturas de $1200{ }^{\circ} \mathrm{C}$ a $1400^{\circ} \mathrm{C}$.

[Table IV-Technical characterization of compositions A, B, C, and D. Green and fired bodies at $1200{ }^{\circ} \mathrm{C}, 1300{ }^{\circ} \mathrm{C}$ and $1400^{\circ} \mathrm{C}$.]

\begin{tabular}{|c|c|c|c|c|}
\hline Composição & A & B & $\mathrm{C}$ & $\mathrm{D}$ \\
\hline $\begin{array}{c}\text { Dens. a seco }(\mathrm{g} / \\
\left.\mathrm{cm}^{3}\right) \\
1200^{\circ} \mathrm{C}\end{array}$ & $1,72 \pm 0,02$ & $1,68 \pm 0,03$ & $1,65 \pm 0,04$ & $1,63 \pm 0,03$ \\
\hline RL $(\%)$ & $2,18 \pm 0,07$ & $2,19 \pm 0,10$ & $2,35 \pm 0,04$ & $2,41 \pm 0,03$ \\
\hline A.A. $(\%)$ & $23,72 \pm 1,59$ & $24,33 \pm 1,50$ & $25,23 \pm 1,61$ & $25,83 \pm 0,33$ \\
\hline P. ap. (\%) & $38,95 \pm 1,63$ & $39,49 \pm 1,49$ & $40,35 \pm 1,60$ & $40,96 \pm 0,43$ \\
\hline D. ap. $\left(\mathrm{g} / \mathrm{cm}^{3}\right)$ & $1,64 \pm 0,04$ & $1,63 \pm 0,04$ & $1,60 \pm 0,04$ & $1,59 \pm 0,01$ \\
\hline RM (MPa) & $3,1 \pm 0,5$ & $2,9 \pm 0,4$ & $2,8 \pm 0,2$ & $2,6 \pm 0,3$ \\
\hline \multicolumn{5}{|l|}{$1300^{\circ} \mathrm{C}$} \\
\hline RL (\%) & $3,75 \pm 0,05$ & $3,81 \pm 0,03$ & $3,97 \pm 009$ & $4,08 \pm 0,06$ \\
\hline A.A. $(\%)$ & $17,56 \pm 0,49$ & $18,91 \pm 0,25$ & $19,51 \pm 0,22$ & $20,84 \pm 1,16$ \\
\hline P. ap. (\%) & $31,79 \pm 0,56$ & $33,24 \pm 0,49$ & $33,50 \pm 0,27$ & $34,98 \pm 1,32$ \\
\hline D. ap. $\left(\mathrm{g} / \mathrm{cm}^{3}\right)$ & $1,81 \pm 0,02$ & $1,76 \pm 0,01$ & $1,72 \pm 0,01$ & $1,68 \pm 0,03$ \\
\hline RM (MPa) & $8,5 \pm 0,6$ & $8,4 \pm 0,8$ & $7,9 \pm 0,2$ & $7,8 \pm 0,6$ \\
\hline \multicolumn{5}{|l|}{$1400{ }^{\circ} \mathrm{C}$} \\
\hline RL (\%) & $5,48 \pm 0,07$ & $5,56 \pm 0,06$ & $5,82 \pm 0,04$ & $6,01 \pm 0,13$ \\
\hline A.A. $(\%)$ & $13,30 \pm 0,51$ & $14,13 \pm 0,43$ & $14,49 \pm 0,7$ & $14,80 \pm 0,7$ \\
\hline P. ap. $(\%)$ & $25,66 \pm 0,87$ & $26,81 \pm 0,54$ & $26,91 \pm 1,10$ & $27,24 \pm 1,06$ \\
\hline D. ap. $\left(\mathrm{g} / \mathrm{cm}^{3}\right)$ & $1,93 \pm 0,01$ & $1,90 \pm 0,03$ & $1,86 \pm 0,02$ & $1,84 \pm 0,02$ \\
\hline RM (MPa) & $15,9 \pm 1,1$ & $15,4 \pm 1,8$ & $15,2 \pm 1,0$ & $15,0 \pm 1,18$ \\
\hline
\end{tabular}


obtidos foram submetidos a três temperaturas de queima. Os resultados dos ensaios de caracterização tecnológica podem ser visualizados na Tabela IV.

A Fig. 3 mostra que as curvas de gresificação das amostras A, B, C e D são características de materiais com formação de fase vítrea, nos quais uma elevação na temperatura ocasiona uma redução da absorção de água e um aumento da retração linear. $\mathrm{O}$ efeito do catalisador sobre as formulações estudadas é pequeno, reduzindo o empacotamento inicial (Tabela IV). Por outro lado, por ser um material poroso sua relação massa/volume também é menor. Estes fatores refletem nas densidades finais queimadas; entretanto, em geral, as propriedades finais são similares, como mostram as Figs. 3 e 4, respectivamente.

O aumento da quantidade de catalisador gasto e conseqüente redução do teor de caulim não resultam em alteração da resistência mecânica à flexão (RMF), como pode ser observado na Fig. 4. A variação de RMF fica dentro da margem de erro dos dados experimentais. Isso significa que a presença do catalisador, de composição diferente ao caulim, não interfere na definição das principais propriedades tecnológicas, o que poderia reduzir a RMF.

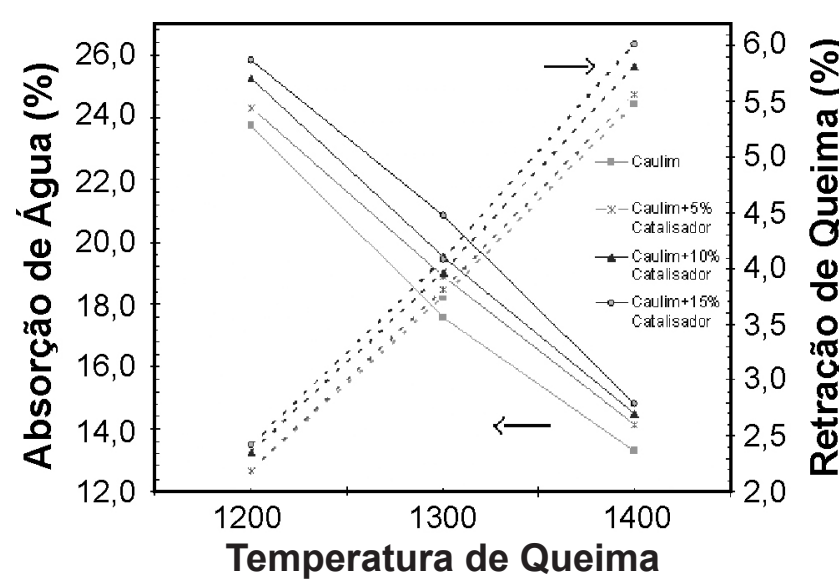

Figura 3: Curvas de gresificação das composições A, B, C e D. [Figure 3: Firing curves of compositions A, B, C, and D.]

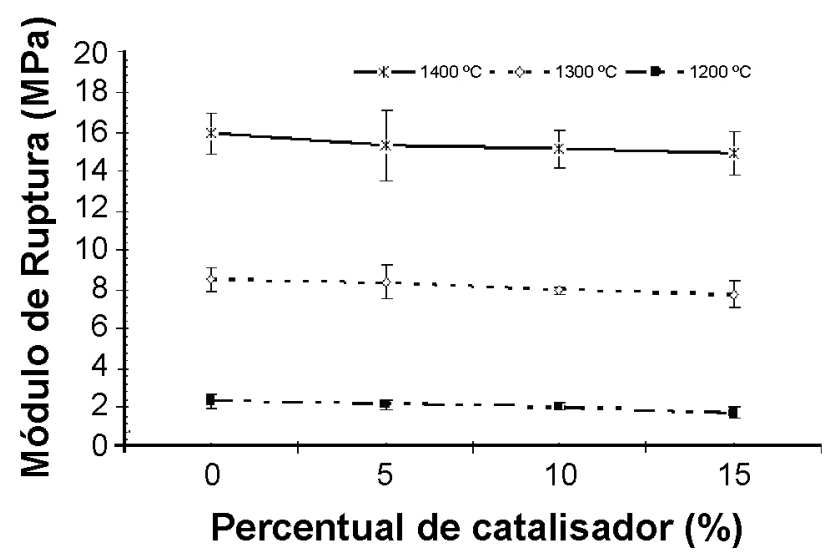

Figura 4: MRF em diferentes temperaturas de queima em função do percentual de catalisador gasto na formulação com caulim.

[Figure 4: MOR at different firing temperatures in function of catalyst waste percentage in kaolin.]
Caracterização dos corpos-de-prova de formulação contendo caulim, catalisador gasto, argila plástica e chamota

Os resultados da caracterização dos corpos-de-prova com a composição E a seco e após sinterização em forno elétrico numa temperatura de $1400{ }^{\circ} \mathrm{C}$, com patamar de 30 min, podem ser visualizados na Tabela $\mathrm{V}$.

Comparando-se os dados referentes à sinterização na temperatura de $1400{ }^{\circ} \mathrm{C}$ das formulações A, D, e E, observase que o acréscimo de argila plástica resultou numa maior gresificação do corpo, mas devido à adição de chamota, as peças da formulação E apresentaram uma menor retração de queima, quando comparadas com as peças de composição A ou D. A avaliação da resistência mecânica revela que a formulação E resultou em peças com valores de resistência mecânica similares à das outras peças, como as peças produzidas somente com o caulim (formulação A).

Tabela V - Caracterização tecnológica da composição E. [Table V-Technical characterization of composition E.]

\begin{tabular}{lr}
\hline Composição & $\mathrm{E}$ \\
\hline Dens. ap. a seco $\left(\mathrm{g} / \mathrm{cm}^{3}\right)$ & $1,66 \pm 0,2$ \\
Perda de peso queimado (\%) & $4,85 \pm 0,02$ \\
RL na queima (\%) & $4,50 \pm 0,10$ \\
RL na requeima* $(\%)$ & $<0,2 \%$ \\
A.A. $(\%)$ & $12,47 \pm 0,43$ \\
Porosidade aparente $(\%)$ & $23,8 \pm 0,67$ \\
Dens. ap. $\left(\mathrm{g} / \mathrm{cm}^{3}\right)$ & $1,91 \pm 0,02$ \\
RM $(\mathrm{MPa})$ & $15,0 \pm 0,4$ \\
\hline * requeima a $1200{ }^{\circ} \mathrm{Cpor} 5 \mathrm{~h}$
\end{tabular}

Na Tabela V, apresenta-se a variação dimensional linear (VDL) na requeima, uma importante propriedade no que se refere à caracterização de produtos refratários, visto que, as tensões geradas pelas mudanças dimensionais permanentes, durante a exposição a um ciclo térmico, poderão provocar trincas no revestimento. Sabe-se que quanto maior o valor do VDL, maior a probabilidade de se gerar trincas [11]. Destaca-se que a variação dimensional resultante da requeima a $1200{ }^{\circ} \mathrm{C}$ por $5 \mathrm{~h}$ para a amostra $\mathrm{E}$ foi menor que $0,2 \%$, sendo este, um valor que já se encontra dentro da faixa de VDL na requeima dos refratários comerciais.

\section{Ensaio do cone pirométrico equivalente}

Para o ensaio de cone pirométrico equivalente foram moldados cones com a composição $\mathrm{E}$, os quais foram aquecidos até a temperatura de $1400{ }^{\circ} \mathrm{C}$ a uma taxa de $150{ }^{\circ} \mathrm{C} / \mathrm{h}$, com patamar de $6 \mathrm{~min}$. Este procedimento é baseado na norma NBR 6222 [10], sendo o resultado apresentado na Fig. 5. Pela análise dessa figura, pode-se verificar que a deformação do cone padrão $13\left(1349^{\circ} \mathrm{C}\right)$ e 


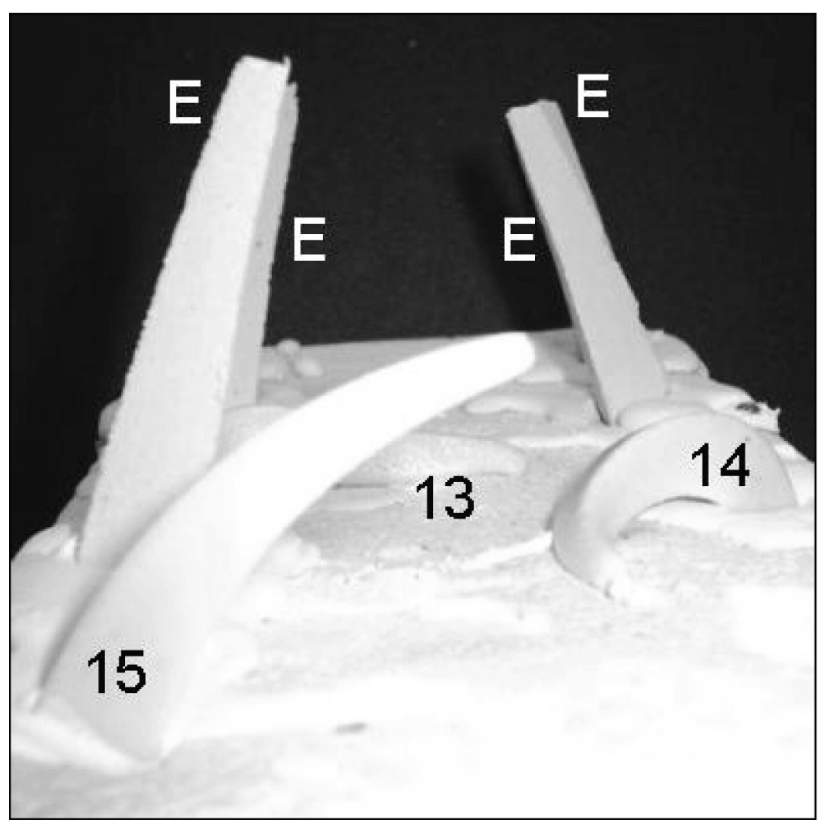

Figura 5: Ensaio do cone pirométrico equivalente da formulação E. Comparação realizada com três cones padrão de numerações: 13 $\left(1349^{\circ} \mathrm{C}\right), 14\left(1398^{\circ} \mathrm{C}\right)$ e $15\left(1430^{\circ} \mathrm{C}\right)$.

[Figure 15: Pyrometric cone assay for composition E. Temperature equivalents for standard cones: $13\left(1349{ }^{\circ} \mathrm{C}\right), 14\left(1398{ }^{\circ} \mathrm{C}\right)$, and $\left.15\left(1430^{\circ} \mathrm{C}\right).\right]$

$14\left(1398^{\circ} \mathrm{C}\right)$ foi completa enquanto a do cone padrão 15 $\left(1430{ }^{\circ} \mathrm{C}\right)$ foi parcial. Os cones de composição E tiveram deformação insignificante, podendo ser classificados como "refratariedade superior ao cone padrão 15 ".

\section{Análise microestrutural}

A Fig. 6 mostra a distribuição do catalisador na matriz, o qual se diferencia da chamota pelo tamanho e formato de partícula. Os poros indicados são provavelmente devido à extração da chamota durante o polimento, na preparação da amostra para essa análise. É possível se observar um espaço anular em volta das partículas de catalisador, o que prova que elas sofrem uma maior retração dimensional em relação à matriz. Este aspecto é mostrado em detalhe na Fig. 7.

$\mathrm{O}$ fato de o catalisador apresentar maior retração que a matriz, explica o porquê dele não exercer o efeito de chamota, reduzindo a retração, uma vez que o mesmo não forma uma rede de contatos de partículas, contribuindo para uma estrutura mais rígida.

A porosidade fornecida pela retração do catalisador, de dimensões de microporosidade (Fig. 7), pode ter um efeito positivo nas propriedades de um refratário, em termos de resistência ao choque térmico [12]. De um modo geral, refratários silicoaluminosos têm porosidade superior a $20 \%$, o que é suficiente para se obter bom isolamento térmico e ter resistência a ciclos térmicos. Neste caso, a presença do catalisador deve contribuir ao desempenho nessas propriedades, uma vez que propicia uma boa distribuição de microporosidade. Por outro lado, por serem poros de

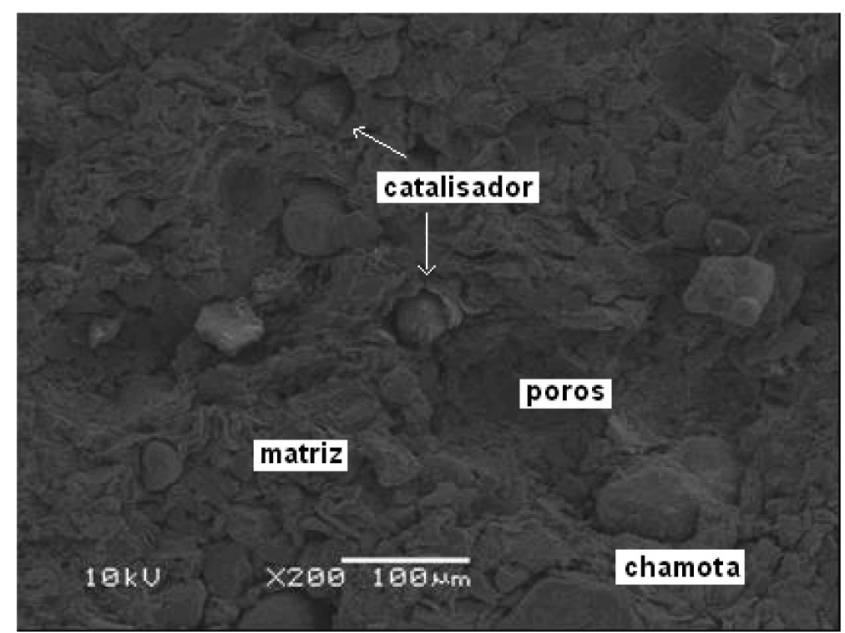

Figura 6: MEV da formulação E. Distribuição do catalisador na matriz.

[Figure 6: SEM of composition E. Catalyst waste distribution in the matrix.]

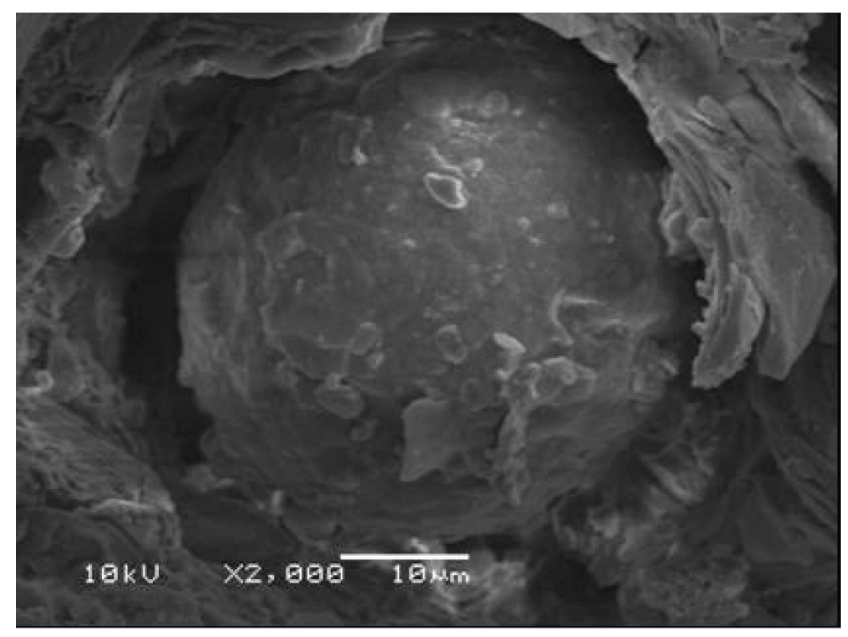

Figura 7: MEV da formulação E. Detalhe do catalisador.

[Figure 7: SEM of composition E. Catalyst waste at higher magnification.]

pequena dimensão, não comprometem a resistência mecânica [13]. Este fato foi comprovado pelos dados na Tabela IV, mostrando que não houve diminuição da RMF com a adição de catalisador.

\section{CONCLUSÃO}

O catalisador gasto apresenta teores de alumina e de sílica dentro da faixa de interesse de matérias-primas para a manufatura de refratários, sendo viável a produção de refratários silicoaluminosos com esse material. Foi possível adicionar à formulação proposta $15 \%$ em peso de catalisador gasto.

A formulação contendo caulim, catalisador gasto, chamota e argila plástica resultou num refratário silicoaluminoso classe SA-2 [7], com teor de alumina de 35\%.

$\mathrm{O}$ refratário desenvolvido apresentou cone pirométrico equivalente 15 ou maior, enquadrando-se dentro da 
classificação de "média exigência" [14]. Esse refratário exibiu uma excelente estabilidade dimensional na requeima a $1200{ }^{\circ} \mathrm{C}$ com patamar de $5 \mathrm{~h}$ (VDL na requeima $<0,2 \%$ ).

$\mathrm{O}$ catalisador gasto teve comportamento refratário nas temperaturas de queima, mantendo a integridade estrutural de suas partículas. Estas, no entanto, apresentaram uma retração superior à matriz, o que propicia uma distribuição de microporosidade na microestrutura do refratário.

\section{REFERÊNCIAS}

[1] E. Abadie, Apostila de Processos de Refino I Craqueamento Catalítico, Petrobrás/RH/UC/DTA (2003).

[2] Associação Brasileira de Normas Técnicas, NBR 1004: resíduos sólidos, Rio de Janeiro, RJ (2004).

[3] Boletim técnico Petrobrás, Recuperação de elementos de zeólitas desativadas, Rio de Janeiro, RJ 46, $3 / 4$ (2003) 351- 365 .

[4] S. R. Bragança, C. P. Bergmann, Materiais refratários e abrasivos, Ed. G. Isaia, Materiais de Construção Civil e Princípios de Ciência e Engenharia de Materiais, vol. 1. S. Paulo, Inracon (2007) 617-653.

[5] D. A. Brosnan, Alumina-silica brick, Ed. C. A. Schacht, Refractories Handbook, Marcel Dekker, Inc. New York, USA (2004) 79-108.
[6] P. S. Santos, Ciência e tecnologia de argilas, vol. 3, Editora Edgard Blücher Ltda., S. Paulo, SP (1989).

[7] Associação Brasileira de Normas Técnicas, NBR 10237: Materiais refratários - Classificação (2001).

[8] Associação Brasileira de Normas Técnicas, NBR 6113: Materiais refratários densos conformados - Determinação da resistência à flexão à temperatura ambiente (1997).

[9] Associação Brasileira de Normas Técnicas, NBR 6220: Materiais refratários densos conformados - Determinação da densidade de massa aparente, porosidade aparente, absorção e densidade aparente da parte sólida (1997).

[10] Associação Brasileira de Normas Técnicas, NBR 6222: Material refratário - Determinação do cone pirométrico equivalente (1995).

[11] A. M. Segadães, Refratários, Universidade de Aveiro, Portugal (1997).

[12] V. C. Pandofelli, M. T. Fadel, Choque térmico em cerâmicas avançadas e refratários, Cerâmica 35, 228 (1989) $1-6$.

[13] R. C. Bradt, Fracture of refractories, Ed. C. A. Schacht, Refractories Handbook, Marcel Dekker, Inc. New York, USA (2004) 11-38.

[14] ASTM C 27 American Standard for Testing Materials - Classification of Fireclay and High-Alumina Refractory Brick (2002).

(Rec.09/07/2008, Ac. 12/09/2008) 